\title{
Role of Mean Platelet Volume in the Prognosis of Gallbladder Carcinoma: A Tertiary Centre Experience
}

\author{
Prakash BV ${ }^{1}$, Ali Z. Anwar ${ }^{1}$, Raghavendra Harsha ${ }^{1}$, Praveen R. Arakeri ${ }^{1}$, Pavan Jonnada ${ }^{1}$ \\ 1. Surgical Oncology, Kidwai Memorial Institute of Oncology, Bengaluru, IND
}

Corresponding author: Ali Z. Anwar, zaidanwar08@gmail.com

\begin{abstract}
Mean platelet volume (MPV) is an inflammatory marker indicative of platelet activation. There are several studies that suggest an association between the neoplastic process and cancer metastasis. We performed a retrospective analysis to investigate the role of MPV as a prognostic informative marker in gallbladder cancer. This study included 73 patients who underwent treatment for gallbladder cancer with curative or palliative intent. MPV was obtained and statistically analysed to investigate the association between the nodal status (N), the overall stage as per the American Joint Committee on Cancer (AJCC) staging system, perineural invasion, and differentiation of the tumor. The statistical analysis was done using SPSS Statistics, version 23 (IBM Corp., Armonk, NY). We found that the MPV values were significantly high in node-positive cases $(\mathrm{OR}=3.623,95 \% \mathrm{CI}=7.778-1.687$, $\mathrm{p}$ value $=-0.0001)$, cases in the advanced stage $(\mathrm{OR}=3.623,95 \% \mathrm{CI}=$ $7.778-1.687, \mathrm{p}$ value $=0.0001)$, cases with perineural invasion $(\mathrm{OR}=3.396,95 \% \mathrm{CI}=8.319-1.387, \mathrm{p}$ value $=$ $-0.0001)$, and poor differentiation $(\mathrm{OR}=2.327,95 \% \mathrm{CI}=4.651-1.164$, $\mathrm{p}$ value $=-0.002)$. MPV is an inexpensive and convenient inflammatory marker that correlates with nodal positivity in the staging and prognostication of gallbladder cancer. This marker can be used to ascertain the risk status of gallbladder cancer.
\end{abstract}

Categories: Medical Education, Gastroenterology, Oncology

Keywords: mean platelet volume, gall bladder cancer, diagnosis, lymph node status, overall stage

\section{Introduction}

Gallbladder cancer is the most common cancer of the hepatobiliary system, with an incidence of $1.2 \%$ of the total cancer diagnoses, accounting for approximately 165,087 deaths and $1.7 \%$ of the total cancer deaths in $2018[1]$.

The presentation of gallbladder cancer is often confusing, which causes delay in diagnosis. It is often discovered incidentally after a simple cholecystectomy or when it causes ascites or jaundice at a very advanced stage [2]. It tends to be unresectable, with a dismal prognosis at stages I, II, III, and IV (60\%, 50\%, $20 \%-25 \%$, and $5 \%-15 \%$, respectively) [3].

Review began 06/23/2021 Review ended 07/04/2021 Published 07/14/2021

\section{(c) Copyright 2021}

$\mathrm{BV}$ et al. This is an open access article distributed under the terms of the Creative Commons Attribution License CC-BY 4.0., which permits unrestricted use, distribution, and reproduction in any medium, provided the original author and source are credited.
Surgery can provide a complete cure when performed in the early stage of the disease, with simple cholecystectomy sufficing for in situ carcinoma or T1a, with a more radical resection needed in the advanced stage if possible where a negative margin is to be obtained, requiring a resection of the liver and bile ducts via a local lymphadenectomy [3,4].

There is limited availability of tumor markers that can be employed in the diagnosis of gallbladder cancer, with carcinoma embryonic antigen (CEA) and carbohydrate antigen (CA) 19-9 being the two most commonly used markers [5]. Other markers, which are not generally used, are CA 15-3, CA 242, and Mac-2BP. However, these have been found to have variable sensitivity and specificity $[5,6]$.

\section{Materials And Methods}

For this study, we retrospectively analysed data on patients with gallbladder cancer at the Kidwai Memorial Institute of Oncology, Bengaluru, India, between January 2018 and January 2021. Data on 73 patients, from the computer database of the institute, was utilized, including data on the staging of the patients according to American Joint Committee on Cancer (AJCC) recommendations and the histological characteristics of the tumor afflicting the patients. The institutional review board clearance was obtained with the proper consent.

For the analysis of mean platelet volume (MPV), a hemogram was obtained from the blood collected, approximately 5 to $10 \mathrm{ml}$ from a peripheral vein into sterilized ethylenediaminetetraacetic acid (EDTA) tubes, from the patients. The blood reports were collected in the morning to minimize circadian rhythm effects, and the MPV value considered was the value at the time of diagnosis of the patient. 


\section{Cureus}

The statistical analysis was performed using the SPSS Statistics, version 23 (IBM Corp., Armonk, NY). The parameters were compared using means and standard deviations, and the parametric variables were compared using chi-square analysis. A receiver-operating characteristic (ROC) curve analysis was performed to identify the optimal cutoff values for MPV. A p value of $<0.05$ was considered significant.

\section{Results}

This study included 73 patients with gallbladder cancer, comprising 49 females and 24 males in the age range of 38 to 82 years, with a mean age of 60.2 years. The patient characteristics are presented in Table 1.

\section{Baseline characters}

Number of patients

Males

Females

Age range 38-82 years

Mean age

60.2 years

Mean platelet volume range

7.30-11.83 fl

Mean platelet volume (mean)

AJCC stage I

AJCC stage II

AJCC stage III

AJCC stage IV

Poor differentiation

Well, moderate differentiation

TABLE 1: Characteristics of study participants

AJCC, American Joint Committee on Cancer

The area under curve was 0.909 for MPV (Figure 1). 


\section{Cureus}

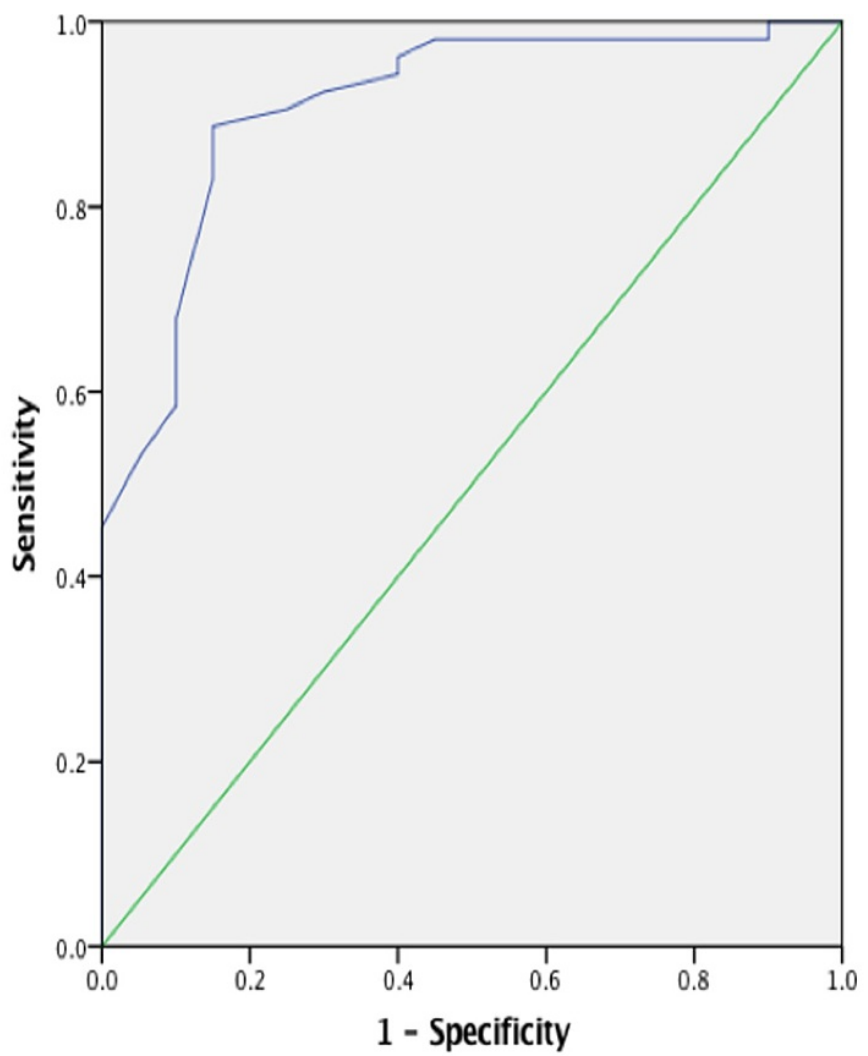

FIGURE 1: Receiver-operating characteristic curve analysis showing the mean platelet volume cutoff

The patients were then divided into two groups: one with a low MPV $(<9.4)$, and the other with a high MPV $(\geqslant 9.4)$.

The MPV values were significantly high in node-positive cases $(\mathrm{OR}=3.623,95 \% \mathrm{CI}=7.778-1.687$, $\mathrm{p}$ value $=$ $-0.0001)$, as shown in Figure 2; advanced stage cases $(\mathrm{OR}=3.623,95 \% \mathrm{CI}=7.778-1.687$, $\mathrm{p}$ value $=0.0001)$, as shown in Figure 3; cases with perineural invasion $(\mathrm{OR}=3.396,95 \% \mathrm{CI}=8.319-1.387$, $\mathrm{p}$ value $=-0.0001)$, as shown in Figure 4; and cases with poor differentiation $(\mathrm{OR}=2.327,95 \% \mathrm{CI}=4,651-1.164$, $\mathrm{p}$ value $=-0.002)$, as shown in Figure 5. There was no significant correlation between high MPV and the age or sex of the patient. There was a negative correlation between high MPV and the age or sex of the patient, as shown in Table 2. 


\section{Cureus}

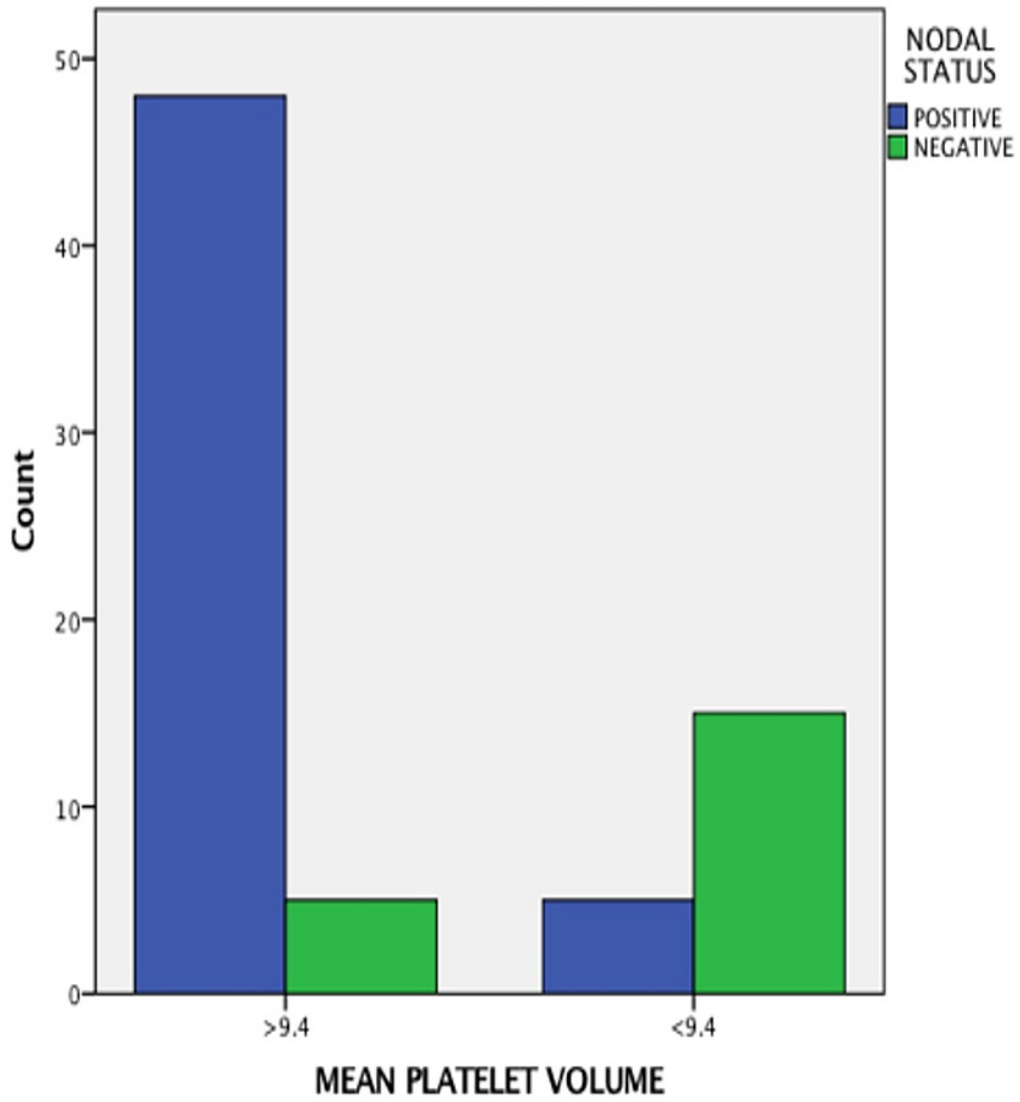

FIGURE 2: Relationship between mean platelet volume and nodal status 


\section{Cureus}

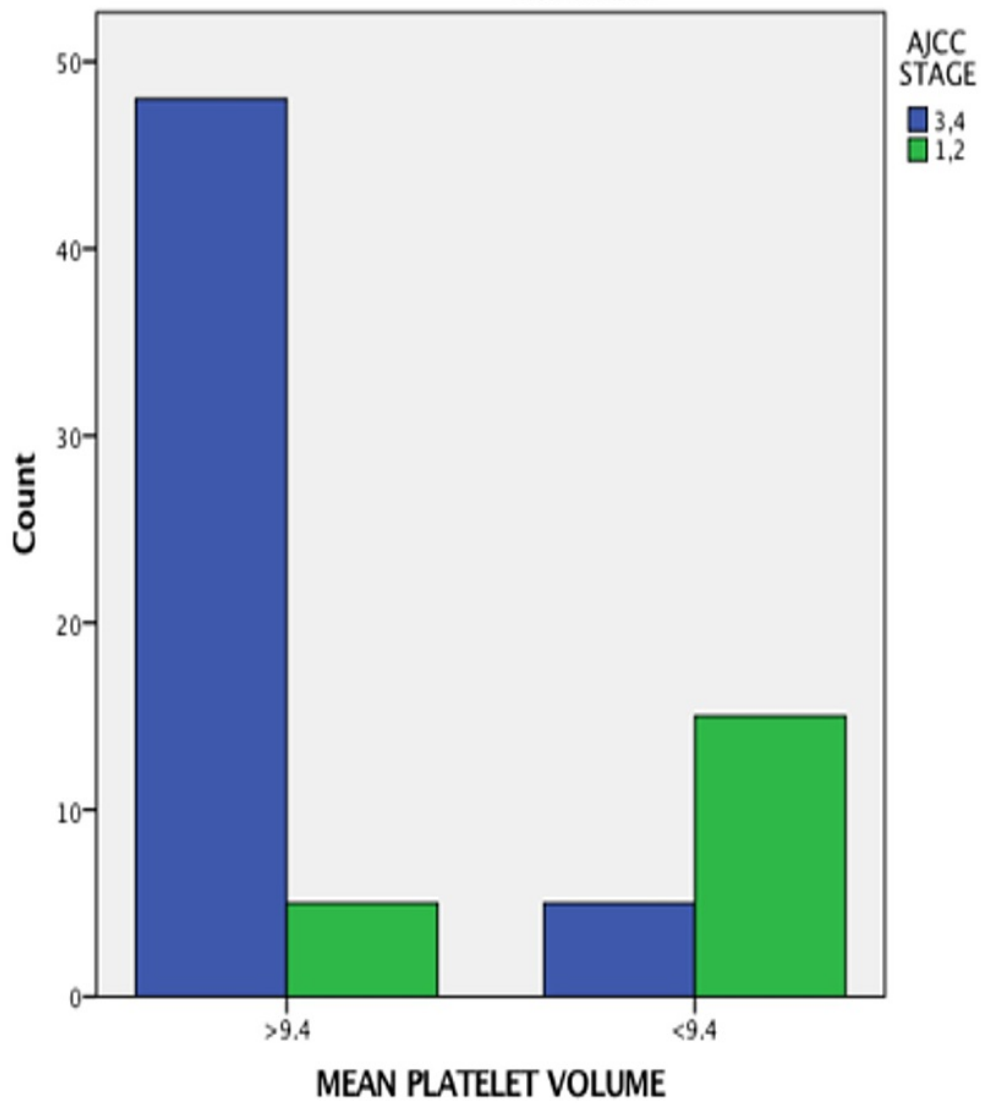

FIGURE 3: Relationship between mean platelet volume and American Joint Committee on Cancer stage 


\section{Cureus}

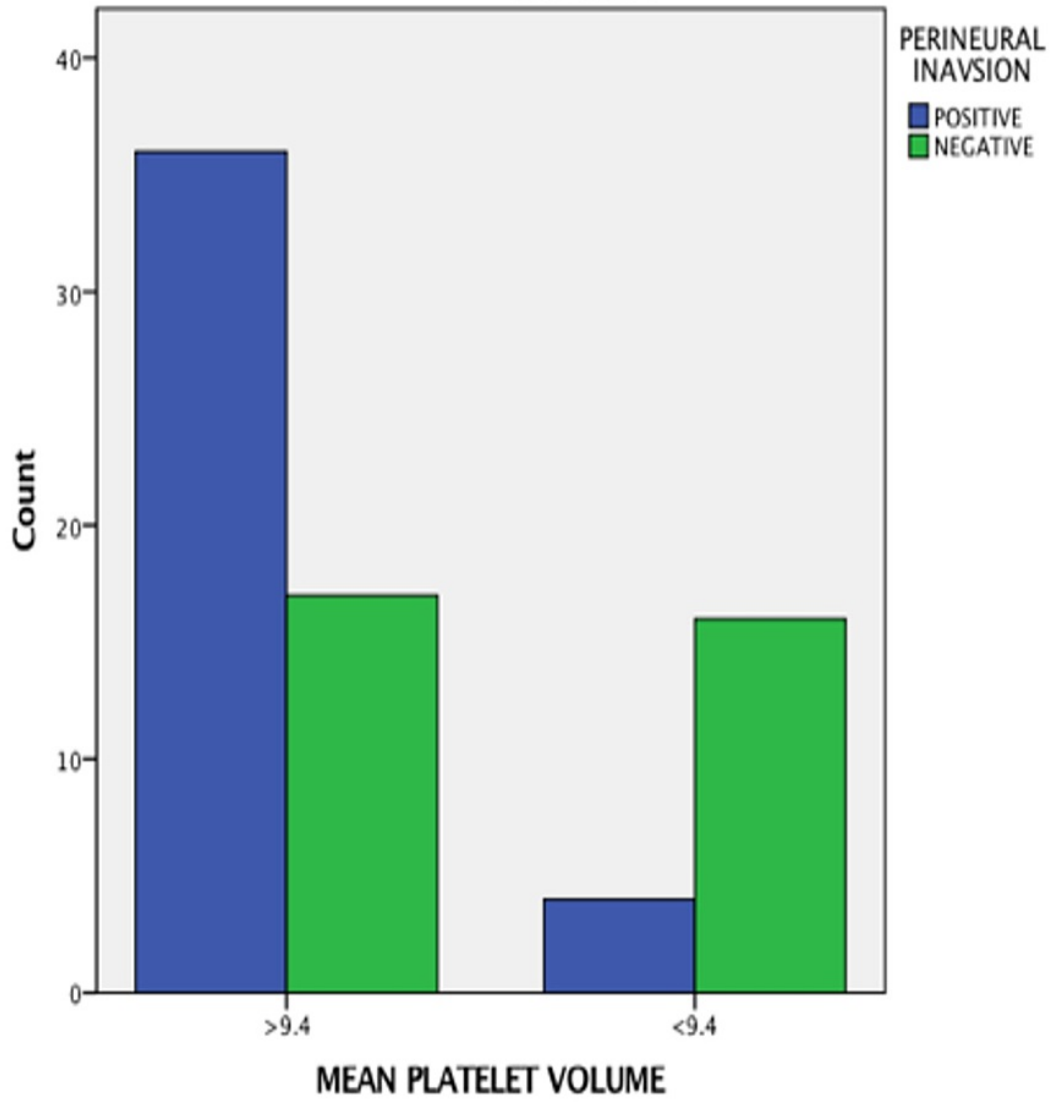

FIGURE 4: Relationship between mean platelet volume and perineural invasion 


\section{Cureus}

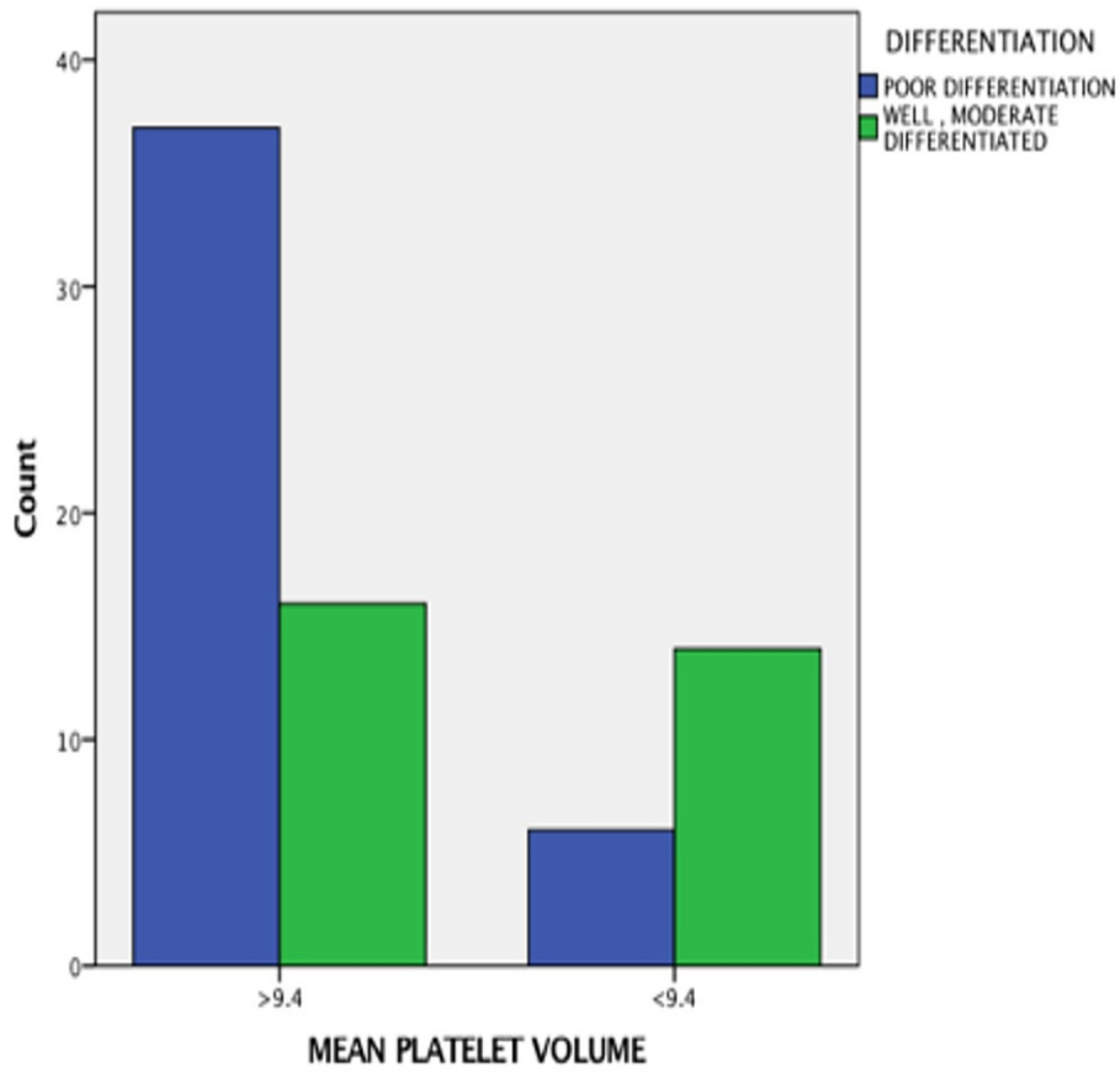

FIGURE 5: Relationship between mean platelet volume and differentiation 


\section{Cureus}

\begin{tabular}{|c|c|c|c|c|c|c|}
\hline & No. of patients & $\begin{array}{l}\text { Low MPV (<9.4 } \\
\text { fl) }\end{array}$ & $\begin{array}{l}\text { High MPV ( } \geq 9.4 \\
\text { fl) }\end{array}$ & Chi-square & value & Odds ratio $(95 \%$ Cl) \\
\hline Gender & & & & 2.07 & 0.15 & $0.77(1.054-0.575)$ \\
\hline Male & 24 & 5 & 19 & & & \\
\hline Female & 49 & 14 & 35 & & & \\
\hline Age & & & & 1.77 & 0.18 & $1.30(2.34-0.81)$ \\
\hline$<60$ years & 31 & 11 & 20 & & & \\
\hline$>60$ years & 42 & 9 & 33 & & & \\
\hline AJCC stage & & & & 31.38 & 0.0001 & $3.623(7.778-1.687)$ \\
\hline Stage I, II & 20 & 15 & 5 & & & \\
\hline Stage III, IV & 53 & 5 & 48 & & & \\
\hline Nodal status & & & & 31.38 & 0.0001 & $3.623(7.778-1.687)$ \\
\hline Node negative & 20 & 15 & 5 & & & \\
\hline Node positive & 53 & 5 & 48 & & & \\
\hline Perineural invasion & & & & 13.464 & 0.0001 & 3.396 (8.319-1.387) \\
\hline Perineural invasion present & 40 & 4 & 36 & & & \\
\hline Perinueral invasion absent & 33 & 16 & 17 & & & \\
\hline Differentiation & & & & 9.507 & 0.002 & $2.327(4.651-1.164)$ \\
\hline Poor differentiation & 43 & 6 & 37 & & & \\
\hline Well, moderate differentiation & 30 & 14 & 16 & & & \\
\hline
\end{tabular}

\section{TABLE 2: Relationship between MPV and demographic and clinical parameters}

AJCC, American Joint Committee on Cancer; MPV, mean platelet volume

\section{Discussion}

In this study, it was observed that an increased MPV value can reliably predict the involvement of lymph nodes in cases of gallbladder cancer. This research shows that MPV is a promising marker that aids in the prediction of advanced stage, perineural invasion, as well as poor differentiation histological characteristics in cases of gallbladder cancer.

An increase in MPV values is generally regarded as the clumping of platelets, which is one of the features of the inflammation processes, which enables the oncogenesis via generation of genetic-material-damaging agents like reactive oxygen species and promotes dissemination and invasion of cancer cells via production of chemokines and various other agents. The increased MPV can also lead to increased platelet depletion and indicates that immature platelets are being released into circulation, which are larger in size than normal platelets [7-10].

Several studies have found a correlation between high MPV values in different cancers. An MPV value higher than $8.25 \mathrm{fl}$ in cases of gastric carcinoma is useful for monitoring patients' risk of gastric carcinoma [11]. In cases of ovarian carcinoma, an MPV value higher than $8.26 \mathrm{fl}$ is correlated with a worse tumor burden and prognosis [12]. In this study, an MPV value greater than $9.4 \mathrm{fl}$ was found to be correlated with worse prognosis, including worse histological features and increased nodal dissemination, as seen in a similar study [13].

However, in a study conducted by Sun et al., it was found that low MPV values of less than $8.10 \mathrm{fl}$ are correlated with a worse prognosis in cases of esophageal carcinoma [13]. However, in other studies including cases of gastric carcinoma, it was found that increased MPV values greater than $10.2 \mathrm{fl}$ were correlated with a worse prognosis and lymph node metastasis [14-16]. 
This study also had some limitations. It was retrospective in nature and was based on case records; the details pertaining to each case were limited in nature. Furthermore, some patients underwent chemotherapy, which may have influenced the attributes of the disease.

This study proves conclusively that there is a correlation between increased MPV values and the local dissemination and prognosis of gallbladder cancer. Although MPV has low specificity at low values, it is a noninvasive, inexpensive marker that can be an invaluable addition to the present repertoire of tumor markers for risk stratification and predicting the prognosis of gallbladder cancer.

\section{Conclusions}

The evaluation and procuring of MPV is quick and inexpensive, making it useful for staging and risk assessment, in addition to being an inflammatory marker. The MPV value of $9.4 \mathrm{fl}$ is the cutoff for predicting nodal metastasis, advanced stage, and worse histological features such as poor differentiation and perineural invasion. Hence, the inclusion of this parameter can facilitate determining the prognosis of the disease.

\section{Additional Information}

\section{Disclosures}

Human subjects: Consent was obtained or waived by all participants in this study. Kidwai Memorial Institute of Oncology issued approval not applicable. It was waived as this was a retrospective study. Animal subjects: All authors have confirmed that this study did not involve animal subjects or tissue. Conflicts of interest: In compliance with the ICMJE uniform disclosure form, all authors declare the following: Payment/services info: All authors have declared that no financial support was received from any organization for the submitted work. Financial relationships: All authors have declared that they have no financial relationships at present or within the previous three years with any organizations that might have an interest in the submitted work. Other relationships: All authors have declared that there are no other relationships or activities that could appear to have influenced the submitted work.

\section{References}

1. Bray F, Ferlay J, Soerjomataram I, Siegel RL, Torre LA, Jemal A: Global cancer statistics 2018: GLOBOCAN estimates of incidence and mortality worldwide for 36 cancers in 185 countries. CA Cancer J Clin. 2018, 68:394-424. 10.3322/caac.21492

2. Batra Y, Pal S, Dutta U, et al.: Gallbladder cancer in India: a dismal picture . J Gastroenterol Hepatol. 2005, 20:309-314. 10.1111/j.1440-1746.2005.03576.x

3. Lee AJ, Chiang YJ, Lee JE, et al.: Validation of American Joint Committee on Cancer eighth staging system for gallbladder cancer and its lymphadenectomy guidelines. J Surg Res. 2018, 230:148-154. 10.1016/j.jss.2018.04.067

4. Zhu AX, Pawlik TM, Kooby DA, Schefter TE, Vauthey JN: Gallbladder. In AJCC Cancer Staging Manual, 8th Edition. Amin MB, Edge S, Greene F, et al. (ed): Springer International Publishing, New York; 2017. 303-309.

5. Srivastava K, Srivastava A, Mittal B: Potential biomarkers in gallbladder cancer: present status and future directions. Biomarkers. 2013, 18:1-9. 10.3109/1354750X.2012.717105

6. Koopmann J, Thuluvath PJ, Zahurak ML, et al.: Mac-2-binding protein is a diagnostic marker for biliary tract carcinoma. Cancer. 2004, 1:1609-1615. 10.1002/cncr.20469

7. Bath PM, Butterworth RJ: Platelet size: measurement, physiology and vascular disease . Blood Coagul Fibrinolysis. 1996, 7:157-161.

8. Kai H, Kitadai Y, Kodama M, et al.: Involvement of proinflammatory cytokines IL-1 $\beta$ and IL-6 in progression of human gastric carcinoma. Anticancer Res. 2005, 25:709-713.

9. Biricik S, Narcı H, Dündar GA, Ayrık C, Türkmenoğlu MÖ: Mean platelet volume and the ratio of mean platelet volume to platelet count in the diagnosis of acute appendicitis. Am J Emerg Med. 2019, 37:411-414. 10.1016/j.ajem.2018.05.075

10. Goubran HA, Stakiw J, Radosevic M, Burnouf T: Platelet-cancer interactions. Semin Thromb Hemost. 2014, 40:296-305. 10.1055/s-0034-1370767

11. Kılınçalp S, Ekiz F, Başar O, et al.: Mean platelet volume could be possible biomarker in early diagnosis and monitoring of gastric cancer. Platelets. 2014, 25:592-594. 10.3109/09537104.2013.783689

12. Kemal Y, Demirağ G, Ekiz K, Yücel I: Mean platelet volume could be a useful biomarker for monitoring epithelial ovarian cancer. J Obstet Gynaecol. 2014, 34:515-518. 10.3109/01443615.2014.912620

13. Sun SY, Zhao BQ, Wang J, Mo ZX, Zhao YN, Wang Y, He J: The clinical implications of mean platelet volume and mean platelet volume/platelet count ratio in locally advanced esophageal squamous cell carcinoma. Dis Esophagus. 2018, 31:dox125. 10.1093/dote/dox125

14. Shen XM, Xia YY, Lian L, et al.: Mean platelet volume provides beneficial diagnostic and prognostic information for patients with resectable gastric cancer. Oncol Lett. 2016, 12:2501-2506. 10.3892/ol.2016.4913

15. K V M, Jonnada P, N SK, Anwar A: Role of mean platelet volume in the prognosis of locally advanced gastric cancer: a tertiary cancer center experience. Cureus. 2020, 12:e9109. 10.7759/cureus.9109

16. Zhang X, Niu Y, Wang X, Liu ZP, Liu T, Wang RT: Mean platelet volume and platelet distribution width are associated with gallbladder cancer. Asian Pac J Cancer Prev. 2018, 26:351-355.

10.22034/APJCP.2018.19.2.351 